\title{
mRNA Expression of Bax, Bcl-2, p53, Cathepsin B, Caspase-3 and Caspase-9 in the HepG2 Cell Line Following Induction by a Novel Monoclonal Ab Hep88 mAb: Cross-Talk for Paraptosis and Apoptosis
}

\author{
Thantip Mitupatum ${ }^{1}$, Kalaya Aree ${ }^{1}$,Suthathip Kittisenachai ${ }^{2}$,Sittiruk Roytrakul ${ }^{2}$, \\ Songchan Puthong ${ }^{3}$, Sasichai Kangsadalampai ${ }^{1}$, Panadda Rojpibulstit ${ }^{1 *}$
}

\begin{abstract}
Monoclonal antibodies with specific antigens have been widely used as targeted therapy for cancer. Hep88 mAb is a monoclonal antibody which shows specific binding with anti-cancer effects against the HepG2 cell line. However, its mechanisms of action are still not completely understood. We examined cell cycling and apoptosis by flow cytometry and mRNA expression of factors involved in apoptosis and paraptosis in Hep88 mAb-treated HepG2 cells by real-time PCR. The cell-cycle analysis demonstrated that growth-inhibitory activity was associated with G2/M cell cycle arrest. Hep88 mAb induced a significant increase in apoptotic cell populations in a dose- and time-dependent manner. The mRNA expression results also suggested that the process triggered by $\mathrm{Hep88} \mathrm{mAb}$ involved up-regulation of tumor suppressor $p 53$, pro-apoptotic Bax, Cathepsin B, Caspase-3 and Caspase-9, with a decrease of anti-apoptotic $B c l-2$ - thus confirming paraptosis and apoptosis programmed cell death. These findings represent new insights into the molecular mechanisms underlying the anti-cancer properties of Hep88 mAb in liver cancer cells.
\end{abstract}

Keywords: Apoptosis - cell cycle arrest - monoclonal antibody - mRNA expression - paraptosis

Asian Pac J Cancer Prev, 17 (2), 703-712

\section{Introduction}

Generally, the cancer cells often evade apoptosis by expressing anti-apoptotic proteins, down-regulation of pro-apoptotic genes and alteration in the signaling pathways that let them survive. Hence, many researchers have been concentrated the development and discovery of the route for cancer cell apoptosis cell death induction. There are two main signaling pathways to trigger apoptosis: the intrinsic apoptotic pathway and the extrinsic apoptotic pathway. The intrinsic apoptotic pathway is activated in response to a number of stress conditions including DNA damage, oxidative stress and many others. The extrinsic apoptotic pathway indicates a form of death that is induced by extracellular signals and through their binding to death receptors. Presently, many evidences indicating the existence of caspase constitute the important mediators of apoptosis program cell death.

On the other hand, researchers have recently witnessed a novel concept for program cell death (PCD) that includes caspase-independent PCD. It is induced by a large number of death-inducing factors to form lysosomal membrane permeabilization (LMP) and/or mitochondrial outer membrane permeabilization (MOMP). Several proteins among the mitochondrial proteins are released to stimulate caspase-independent PCD. Meanwhile proteolytic enzymes in lysosome-like cathepsins are also released to degrade intracellular proteins or activate caspases, as well as other enzymes, to induce cell death. It is now recognized this type of PCD, as apoptosis-like PCD or paraptosis by morphological characterization, differs from apoptosis, i.e. numerous vacuolization without apoptotic body or membrane blebbing. The mechanism involving paraptosis has also demonstrated scientifically that it is involved in cathepsins activation but has not responded to caspase inhibitors and caspases activation (Sperandio et al., 2004).

However, the cell can also lead to apoptosis program cell death via the dysfunction of tumor suppressor proteins. One of those that are outstanding in its being recognized as involved in apoptosis is the $p 53$ protein. $p 53$ plays a crucial role in cell cycle and apoptosis as a tumor suppressor in the arresting of the cell cycle or the elimination of DNA-

${ }^{1}$ Faculty of Medicine, Thammasat University (Rangsit Campus), ${ }^{2}$ Thailand National Center for Genetic Engineering and Biotechnology (BIOTEC), Thailand Science Park, Pathum Thani, ${ }^{3}$ Antibody Production Research Unit, Institute of Biotechnology and Genetic Engineering, Chulalongkorn University, Bangkok, Thailand *For correspondence: panadda_rojpibulstit@hotmail.com 
damaged cells. In the sense of apoptosis, $p 53$ can mediate apoptosis through transcriptional activation of various pro-apoptotic target genes, such as Bax, or through the repression of those of anti-apoptotic genes (Chiang et al., 2014). Hence, most cases of cancer cells, deregulation of p53 by mutation, post-translation modification or even interaction with other proteins will induce the cells to become cancerous. For example; mortalin-p53 interaction was shown to cause inactivation of $p 53$ activities that are scientifically proven to be involved in tumorigenesis. As a result, targeted therapy to recover $p 53$ function is currently being studied extensively and in detail. One such effective tool includes the production of monoclonal antibody that is recognized with a $p 53$-deregulated protein such as Hep88 mAb.

Hep88 mAb is the monoclonal antibody specific to mortalin HSP70 in hepatocellular carcinoma (Laohathai and Bhamarapravati, 1985; Rojpibulstit et al., 2014). It has been shown to have anti-cancer effects against HepG2 cell line, but harmless otherwise to the normal liver cell line (Puthong et al., 2009). The death of HCC induced by Hep88 mAb was formerly demonstrated by way of a paraptosis-like program cell death (paraptosis-like PCD) character (Manochantr et al., 2011). However, the focus of many reports has been that various types of cell death could be triggered by multiple mechanisms, whereas the morphological changes might be detected by one which is predominant. We then also reported that Hep88 $\mathrm{mAb}$ induced paraptosis-like PCD by up-regulation of Caspase-3, -8 and -9 , as well as its activity after 24-hr of incubation (Mitupatum et al., 2015). These findings prompted us to conclude that Hep $88 \mathrm{mAb}$ did in fact induce $\mathrm{HCC}$ from a paraptosis-like state to apoptosis by the downstream induction of caspases. However, we were still left with the question of vacuolization morphologynamely, whether or not Hep88 mAb was involved in lysosomal breakdown. In this study, we have conducted our tests by increasing the cytotoxic doses of Hep88 $\mathrm{mAb}$ treatment to explore the apoptosis induction and the involvement of mitochondria and lysosome in HCC. The HCC cell lines were treated with Hep $88 \mathrm{mAb}$ and we then evaluated the induction of apoptosis, cell cycle arrest, and mRNA expression of Bax, Bcl-2, p53, Cathepsin B, Caspase- 3 and Caspase-9.

\section{Materials and Methods}

\section{Materials}

Fetal bovine serum, Trypsin/EDTA Solution and PBS solution were obtained from Biochrom (AG, Berlin). TRI REAGENT® was obtained from Molecular research center, Inc. The oligo nucleotide primers (oligoDT primer), 2X KAPA SYBR® FAST qPCR Master Mix were obtained from KapaBiosystems, Inc.(Wilmington, MA, USA). SuprimeScript RT premix (2X) was obtained from GENET BIO (Daejeon, Korea). The QIAprep ${ }^{\circledR}$ Spin Miniprep Kit was obtained from QIAGEN (Hilden, Germany). PCR Master Mix (2X) and InsTAclone PCR Cloning Kit were obtained from Thermo Fisher Scientific (Pittsburgh, PA, USA). The FITC Annexin V Apoptosis Detection Kit I, PI/RNase staining buffer, BDFACS Rinse solution, BD FACS Clean solution and BD FACS Flow Sheath Fluid were purchased from BD Biosciences (CA, USA).

\section{Cell Lines and $m A b$}

The human HCC cell lines, specifically the HepG2 cells (American Type Culture Collection [ATCC] HB8065), were cultured in RPMI 1640 supplemented with $10 \%$ fetal bovine serum (Biochrom AG, Germany).The cell lines were maintained at $37^{\circ} \mathrm{C}$ in a $\mathrm{CO}_{2}$ incubator and subculture every 3-4 days until use. Hep $88 \mathrm{mAb}$, the antiHCC mouse mAb, was produced as previously described (Laohathai and Bhamarapravati, 1985).

\section{Treatment of HepG2 Cells with Hep88 mAb}

HepG2 cells were cultured in RPMI 1640 medium containing $10 \%$ fetal bovine serum at $37{ }^{\circ} \mathrm{C}$ in $5 \% \mathrm{CO}_{2}$ for $24-\mathrm{hr}$ prior to treatment. From our previous study, it was found that a cytotoxicity dose of Hep $88 \mathrm{mAb}$ contained a concentration of 5 times that of the $\mathrm{IC}_{50}(12.5 \mu \mathrm{g} / \mathrm{ml})$. Hence, it was necessary to monitor its apoptotic response while varying time and dose for apoptosis detection and cell-cycle progression by flow cytometry analysis. For this purpose, it was decided to treat the HepG 2 cells with 4-6 times the $\mathrm{IC}_{50}$ concentration of Hep88 mAb (i.e. 50, 62.5 and $75 \mu \mathrm{g} / \mathrm{ml}$ ), paralleling untreated HepG2 cells as the negative control. After 24, 48 and 72-hr of incubation, the cells were trypsinized and were then washed twice with iced-cold PBS. The cell was collected for the next step in flow cytometry analysis.

Additionally, mRNA expression analysis was performed by HepG2 cells treated with a cytotoxic concentration of $62.5 \mathrm{ug} / \mathrm{ml} \mathrm{Hep} 88 \mathrm{mAb}$. To investigate its time-dependent manner, the cells were incubated in two sets: i.e. for 12-, 18- and 24-hr in the case of one set for Bax, Bcl-2, p53, Cathepsin B, Caspase-3, Caspase-9 and $E F-2$ gene. The other set was designed to investigate a nearly response which was formerly notified as paraptosis morphology. The incubation thus performed in an earlier incubation period (at 3-, 6-, 9-hr of treatment) was then carried out as an mRNA expression of Bax, Bcl-2, p53, Cathepsin B, Caspase-3, Caspase-9 and EF-2 gene. The untreated HepG2 cells at each time and dose were used as controls. After incubation, the cells were extracted for total RNA by TRI REAGENT® (Molecular research center, Inc).

\section{Apoptosis detection}

Treated- and untreated-HepG2 cell pellets were stained with the FITC Annexin V Apoptosis Detection Kit I (BD Pharmingen ${ }^{\mathrm{TM}}$, CA, USA) according to the manufacturing protocol. The suspension was analyzed with a fluorescence-activated cell sorter (FACS, BD FACSCalibur $^{\mathrm{TM}}$, BD Biosciences, CA, USA). The percentages of cells were calculated by CellQuest ${ }^{\mathrm{TM}}$ software (BD Biosciences, CA, USA). The cells in the early stages of apoptosis were annexin $\mathrm{V}$ positive and PI negative, while the cells in the late stages of apoptosis were both annexin $\mathrm{V}$ and PI positive.

Cell cycle progression 
mRNA Expression of Bax, Bcl-2, p53, Cathepsin b, Caspase-3 and Caspase-9 in the HepG2 Cell Line with Hep88 mAb

After the cells had been cultivated, operated on and collected as described above, they were then washed and fixed in $90 \%$ ethanol at $-20^{\circ} \mathrm{C}$ overnight. The cell were stained with PI/RNase staining buffer (BD Biosciences, CA, USA) at room temperature away from sunlight for 15 minutes and analyzed with a fluorescence-activated cell sorter (FACS, BD FACSCalibur ${ }^{\mathrm{TM}}$, BD Biosciences, CA, USA). Data were analyzed using ModFit LT 3.2.

\section{RNA extraction and cDNA synthesis}

RNA extraction and cDNA synthesis was performed as describe previously (Mitupatum et al., 2015). In brief, the steps would be as followed: (1) extraction of total RNA by TRI REAGENT ${ }^{\circledR}$ referring to the manufacturer's instruction (Molecular research center, Inc), (2) quantization of RNA's concentration and purity by NanoDrop 1000 Spectrophotometer (NanoDrop Technologies, Inc. Wilmington, DE, USA), (3) complementary DNA (cDNA) synthesis by reverse transcription reaction, (4) quantization of cDNA concentration by NanoDrop 1000 Spectrophotometer.

\section{Plasmids construction and copy number determination}

Plasmids Construction of Bax, Bcl-2, p53, Cathepsin $B$, Caspase-3, Caspase- 9 and $E F-2$ gene were performed as previously described (Mitupatum et al., 2015). In brief, the PCR product of those amplified genes with the primer sets as shown in Table 1 was cloned into the TA cloning vector pTZ57R/T using the InsTAclone PCR Cloning Kit (Thermo Fisher Scientific, Pittsburgh, PA, USA). After transformation into competent cells (E. coli DH5 $\alpha$ ), the transformed cells were cultured and isolated for plasmid DNA by the QIAprep ${ }^{\circledR}$ Spin Miniprep Kit (QIAGEN, Hilden, Germany) before sequencing by Macrogen Inc. (Korea) with the 96-capillary 3730xl DNA Analyzer (Applied Biosystems ${ }^{\circledR}$ ). Serial dilutions of plasmid DNA were performed before being added into the real-time PCR Master Mix. The gene expression analysis was carried out using the Exicycler ${ }^{\mathrm{TM}} 96$ Bioneer (Bioneer Corporation, Daejoen, Korea). Ct value of each dilution was determined and then used to generate the standard curve against the logarithms of their own corresponding copy numbers. The curve was calculated by use of the equation previously described (Whelan et al., 2003).

\section{Real-time PCR}

Real-time PCR was performed by use of the SYBR Green dye (KapaBiosystems, Inc. of Wilmington, MA, USA) on the Exicycler ${ }^{\mathrm{TM}} 96$ Bioneer machine (Bioneer Corporation, Daejoen, Korea). Each PCR reaction took place in triplicate. The forward and reverse primers used for PCR amplification of Bax, Bcl-2, p53, Cathepsin B, Caspase-3, Caspase- 9 and $E F-2$ gene are all listed in Table 1. The PCR reactions were made by mixing $2 X$ KAPA SYBR ${ }^{\circledR}$ FAST qPCR Master Mix (KapaBiosystems, Inc. of Wilmington, MA, USA) with each primer and cDNA template. The real-time PCR program was carried out with a following 1 cycle of initial denaturation at $94^{\circ} \mathrm{C}$ for 10 min through 40 cycles of PCR reaction and then held for 30 seconds at each temperature level. Finally, melting curve analysis was performed over a gradient extending from an annealing to a denaturation temperature. The expression was calculated by using the relative standard curve method of quantification and reported as a fold change of gene expression.

\section{Statistical analysis}

The data were expressed as mean values \pm standard deviation of the mean (SD). Difference between the two groups was analyzed by One-way ANOVA and student's $t$ test. A value of $p<0.05$ was considered statistically significant. Cell-cycle distribution was analyzed by Modfit software.

\section{Results}

HepG2 apoptotic cell death induced by different concentrations of Hep $88 \mathrm{mAb}$

The mode of cell death induced by Hep88 mAb in HepG2 cells was confirmed by annexin V/PI double staining. Hep88 mAb-treated cells induced a decrease in the percentage of viable cells (annexin V-/PI-) as compared to control cells with a concurrent increase in the percentage of early apoptotic cells (annexin V+/PI-). The percentage of early apoptotic cells increased in a dose- and timedependent manner (Figure 1A and 1B). Furthermore, the Hep88 mAb treated HepG2 cells were visualized under the light microscope and found the increasing of death cells

Table 1. Forward and Reverse Primer PCR Sequences for Real-time PCR

\begin{tabular}{|c|c|c|c|c|}
\hline Primers & & Sequence of Nucleotides (nt) & Size (nt) & PCR Product length \\
\hline \multirow[t]{2}{*}{$\operatorname{Bax}\left(55^{\circ} \mathrm{C}\right)$} & Forward & 5'-ATGTTTTCTGACGGCAACTTC-3' & 21 & $133 \mathrm{bp}$ \\
\hline & Reverse & 5'-AGTCCAATGTCCAGCCCAT-3' & 19 & \\
\hline \multirow[t]{2}{*}{$B c l-2\left(65^{\circ} \mathrm{C}\right)$} & Forward & 5'-ATGTGTGTGGAGACCGTCAA-3' & 20 & $141 \mathrm{bp}$ \\
\hline & Reverse & 5'-GCCGTACAGTTCCACAAAGG-3' & 20 & \\
\hline \multirow[t]{2}{*}{ p53 $\left(60^{\circ} \mathrm{C}\right)$} & Forward & 5'-ATGTTTTGCCAACTGGCCAAG-3' & 21 & 153 bp \\
\hline & Reverse & 5'-TGAGCAGCGCTCATGGTG-3' & 18 & \\
\hline \multirow[t]{2}{*}{ Cathepsin $B\left(55^{\circ} \mathrm{C}\right)$} & Forward & 5'-CAGCGTCTCCAATAGCGA-3' & 18 & $164 \mathrm{bp}$ \\
\hline & Reverse & 5'-AGCCCAGGATGCGGAT-3' & 16 & \\
\hline \multirow[t]{2}{*}{$E F-2\left(60^{\circ} \mathrm{C}\right)$} & Forward & 5'-CTGAAGCGGCTGGCTAAGTCTGA-3' & 23 & $155 \mathrm{bp}$ \\
\hline & Reverse & 5'-GGGTCAGATTTCTTGATGGGGATG-3' & 24 & \\
\hline \multirow[t]{2}{*}{ Caspase $-3\left(60^{\circ} \mathrm{C}\right)$} & Forward & 5'-TGTTTGTGTGCTTCTGAGCC-3' & 20 & 210 bp \\
\hline & Reverse & 5'-CACGCCATGTCATCATCAAC-3' & 20 & \\
\hline \multirow[t]{2}{*}{ Caspase $-9\left(65^{\circ} \mathrm{C}\right)$} & Forward & 5'-CATTTCATGGTGGAGGTGAAG-3' & 21 & $149 \mathrm{bp}$ \\
\hline & Reverse & 5'-GGGAACTGCAGGTGGCTG-3' & 18 & \\
\hline
\end{tabular}


Thantip Mitupatum et al

after treated with Hep88 mAb (Figure 1C). The increase in the apoptotic population is associated with the increase in the sub-G1 population observed in the cell cycle analysis (Figure 2). These results suggest that Hep88 mAb induces cell death through an apoptotic mechanism.

HepG2 cell cycle progression induced by different concentrations of Hep $88 \mathrm{mAb}$

Apoptotic cells show staining below the $\mathrm{G} 1$ population of normal diploid cells. The DNA-specific fluorochrome PI identified a distinct hypo-diploid cell (sub-G1) population as apoptotic cells. Figure 2A shows a representative DNAhistogram of HepG2 cells as observed at 24-, 48- and 72-hr after treatment with $50,62.5$ and $75 \mu \mathrm{g} / \mathrm{ml}$ of Hep88 $\mathrm{mAb}$, respectively. The percentages of each phase population were measured by FCM. Populations of apoptotic cells (sub-G1) and G2/M cells were higher in the experimental group than in the control group (Figure 2A and 2B). Furthermore, at the same concentration of Hep88 mAb, apoptotic cells increased over time.

A

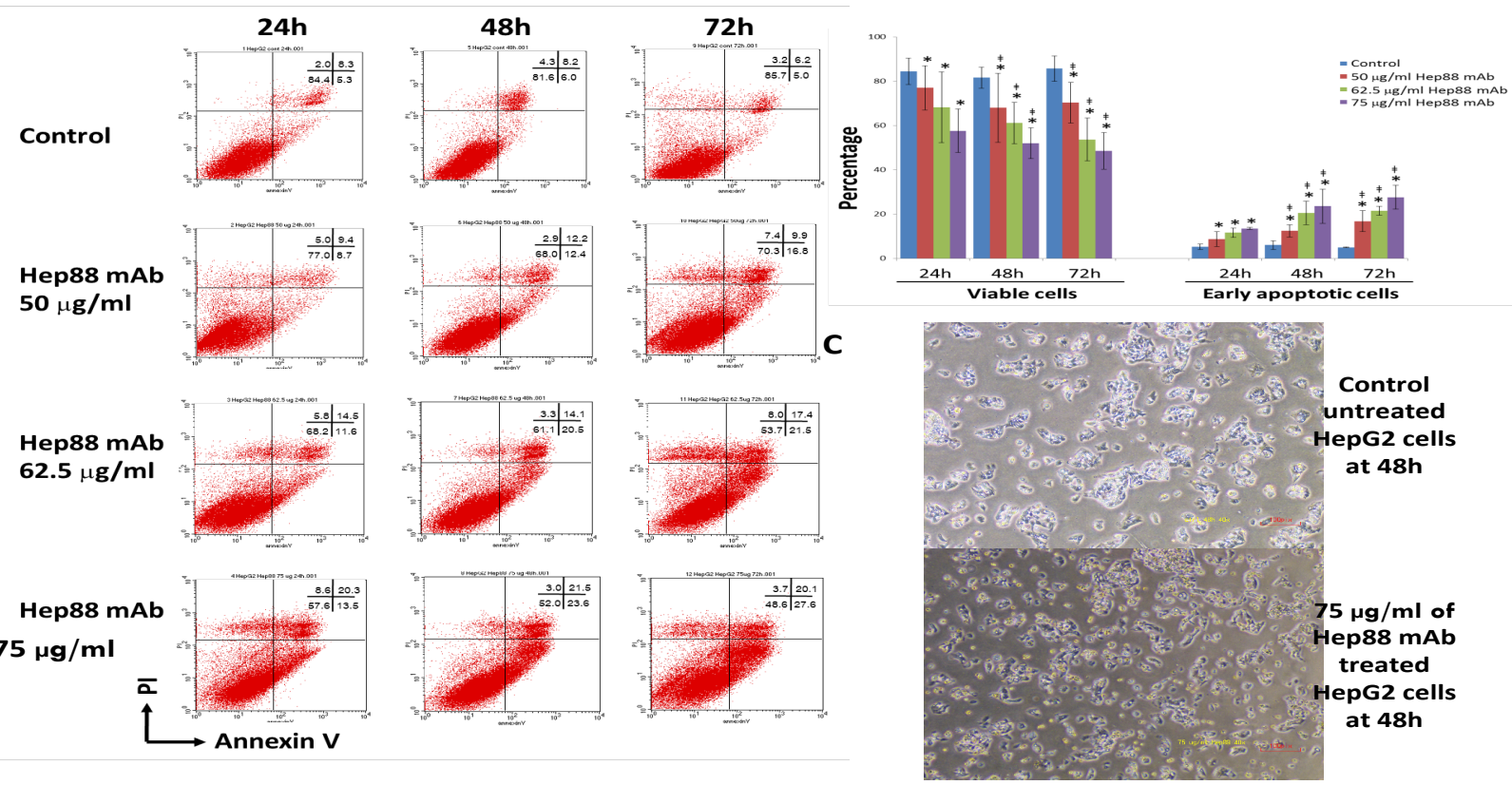

Figure 1. The Apoptotic Cell Death in Hep88 mAb-treated HepG2 Cells. (A) Flow cytometry analysis of apoptotic cell death. (B) The percentage of early apoptotic cells increased in a dose- and time-dependent manner (mean $\pm S D, n \geq 3),{ }^{*}<0.05$ vs. control, $\mathrm{p}<0.0548$ - and 72-hr incubation vs $24-\mathrm{hr}$ incubation of their corresponding doses. (C) The light microscope photomicrograph.

A

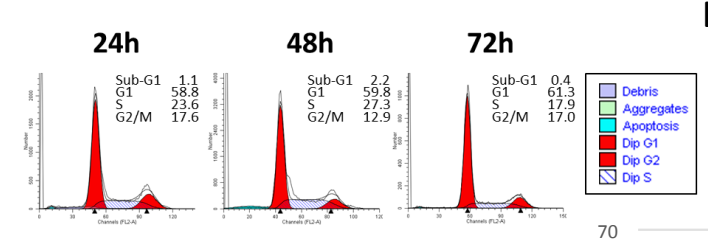

B

Control

$72 \mathrm{~h}$

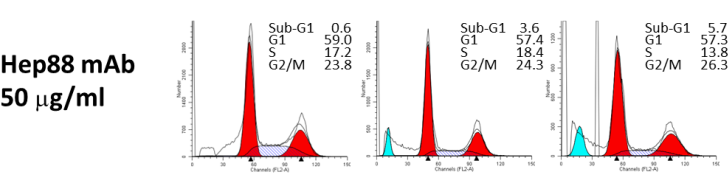

$50 \mu \mathrm{g} / \mathrm{ml}$

Hep88 mAb $62.5 \mu \mathrm{g} / \mathrm{ml}$


Cell cycle of HepG2 cell

Figure 2. Effects on Varying Doses and Times of Hep88 mAb Incubation on Cell Cycle Progression in HepG2

Cells. (A) The histograms of cell cycle at 24-, 48- and 72-hr in varying doses. (B) The G2/M cell cycle arrest and apoptosis (sub-G1) were significant increase in doses and incubation times of Hep88 mAb treatment, ${ }^{*} \mathrm{p}<0.05$ vs. control 
mRNA Expression of Bax, Bcl-2, p53, Cathepsin b, Caspase-3 and Caspase-9 in the HepG2 Cell Line with Hep88 mAb

Plasmids construction and copy-number determination

After plasmid quantification, the copy numbers of each gene were then calculated. The standard curves of genes were then formed. A linear plot was shown in the range tested for $\mathrm{R}^{2}=0.995($ Bax $), \mathrm{R}^{2}=0.997\left(\right.$ Bcl-2), $\mathrm{R}^{2}=0.991$ (p53) $\mathrm{R}^{2}=0.999$ (cathepsin-B), $\mathrm{R}^{2}=0.992$ (Caspase -3$)$, $\mathrm{R}^{2}=0.996$ (Caspase-9), and $\mathrm{R}^{2}=0.997(E F-2)$.

\section{Real-time PCR}

Statistically significant differences in fold change of the mRNA expression levels of $\mathrm{Bax}, \mathrm{Bcl}-2, \mathrm{p53}$, Cathepsin
A

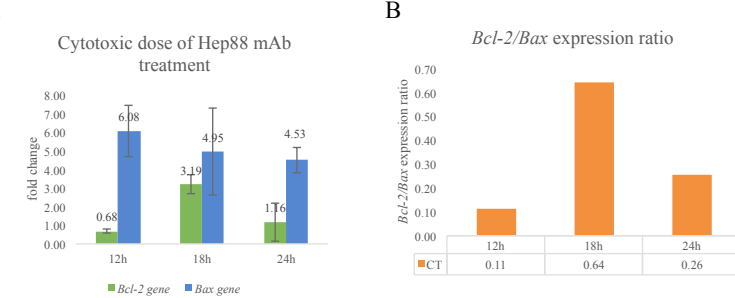

Figure 3. Real-time PCR Analysis for $B c l-2$ mRNA expression, Bax mRNA Expression and the Ratio of $B c l-2 / B a x$ after Cytotoxic Treatment with Hep88 mAb at 12, 18 and 24-hr. (A) Graph represents the up-regulation of $B a x$ mRNA expression. (B) The chart shows the Bcl-2/Bax expression ratio with a value lower than 1 . These results strongly supported the apoptosis induction of Hep $88 \mathrm{mAb}$ through an up-regulation of Bax together with a down-regulation of $\mathrm{Bcl}-2$
B, Caspase-3 and Caspase-9 in Hep 88 mAb-treated HepG2 cell as compared with the untreated cells by realtime PCR is shown $(\mathrm{p}<0.05)$ (Figure 3, 4 and 5). Figure $3 \mathrm{~A}$ represents the up-regulation of pro-apoptotic gene, $B a x$, over the anti-apoptotic one, $B c l-2$, at any one time of treatment. Interestingly, $\mathrm{Bcl}-2 / \mathrm{Bax}$ expression ratio decreased to a level below one (Figure 3B). This pattern strongly supported the apoptotic induction of Hep88 mAb through up-regulation of Bax mRNA expression while supporting the down-regulation of $\mathrm{Bcl}-2 \mathrm{mRNA}$ expression.

In addition, it has been demonstrated that the Bax and Caspase-9 mRNA expression were consistent with the p53 mRNA expression throughout the period of treatment (Figure 4A). It shows up- and down- and up- significant regulation response from the start to the completion of treatment (with 12-, 18- and 24-hr of incubation times). On the other hand, a flipped response was found at the $\mathrm{Bcl}-2$ mRNA expression (Figure 4B). To monitor the response of p53, Bax and Caspase- 9 mRNA expression at the earlier time of treatment, we also conducted the real-time PCR at 3-, 6- and 9-hr of treatment. The results of p53 mRNA expression show a gradual increase in fold change (Figure 5B). It was related to Bax mRNA expression (Figure 5B). Meanwhile, the Caspase- 9 mRNA expression at the earlier time of treatment wasn't correlated to Bax and p53 mRNA expression.

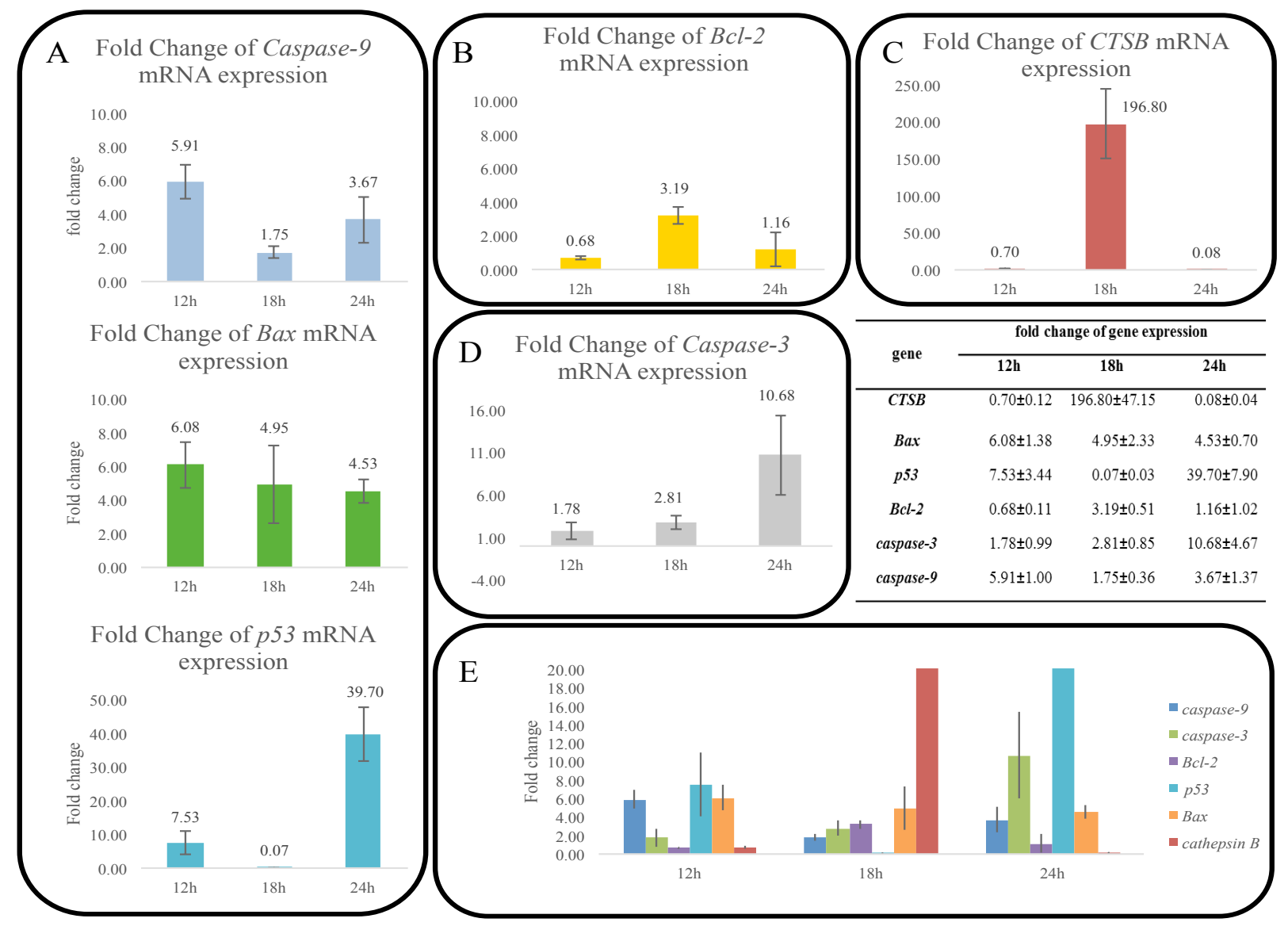

Figure 4. Real-time PCR Analysis for Bax, Bcl-2, p53, Cathepsin B, Caspase-3 and Caspase-9 mRNA Expression after Cytotoxic Treatment of Hep88 mAb at 12-, 18- and 24-hr. (A) The Bax and Caspase-9 were consistent with the p53. (B) Bcl-2 was opposite with Bax. Similarly, (C) the Cathepsin B revealed the up-regulation at 18-hr, while (D) the Caspase-3 was increased after prolonged incubation time. Bar graphs (E) provide an overview of mRNA expressions at 12-, 18- and 24-hr 


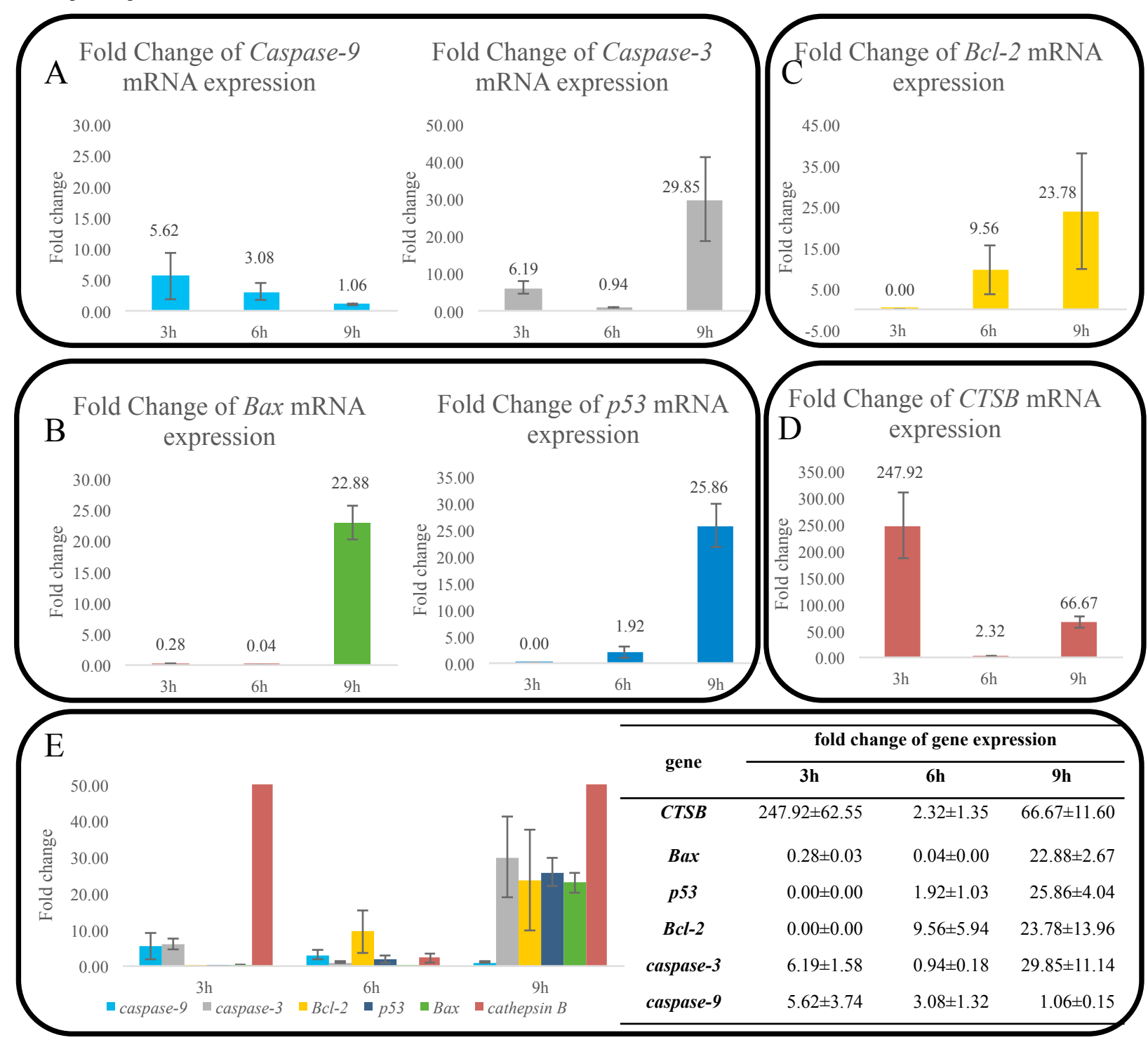

Figure 5. Real-time PCR Analysis for Cathepsin B, Bax, p53, Bcl-2, Caspase-3 and Caspase-9 mRNA Expression in Cytotoxic dose of Hep88 mAb Treatment at 3-, 6- and 9-hr. (A) Graph represents Caspase-9 and Caspase-3 mRNA expressions. (B) Bax and $p 53$ up-regulated at 9-hr. (C) Bcl-2 multiplied increasingly from 6- to 9-hr. (D) The up-regulation of Cathepsin B (CTSB) was found at 3-hr. Bar graphs (E) reveal an overview of mRNA expressions at 3-, 6- and 9-hr

Additionally, as regards the protein involved in paraptosis morphology - i.e. Cathepsin B (CTSB) - it shows a sharply contoured expression (Figure $4 C$ ). The Cathepsin B mRNA expression displays an up-regulation after 18 -hr of treatment while a drop to the lowest expression level is detected both at an early (12-hr) and late treatment (24-hr). This pattern prompted us to reveal the response that would be detected at the earlier point. Figure 5D shows the sharpest up-regulation of the CTSB mRNA expression at the earliest point in time (at 3-hr) of treatment.

However, when focusing on the Caspase-3 mRNA expression (Figure 4D), it is likely to peak with its strongest increase after a prolonged incubation time of treatment, corresponding to flow cytometry results as reported in our former report (Mitupatum et al., 2015). The earlier response of Caspase-3 mRNA expression at 3-, 6- and 9-hr of treatment was also found (Figure 5A).

\section{Discussion}

There is a sizable amount of evidence that suggests the utility of various anti-cancer agents against HCC (Taghiyev et al., 2012), but there are also many restrictions especially the specification to HCC. The present study is approach to manifest novel strategies that more specific for HCC treatment using Hep88 monoclonal antibody. We have investigated Hep 88 mAb-treated HCC to explore whether it dominantly induces apoptosis and whether mitochondria, lysosome and caspases are involved in stimulated cell death in HCC or not. Our research evaluated the induction of apoptosis, cell cycle arrest, and mRNA expression of Bax, Bcl-2, p53, Cathepsin B, Caspase-3 and Caspase-9. The challenge of this study is the differences in anti-cancer effect of Hep88 mAb that was induced through multi-mechanisms of cell death. Our results shown that the induction of apoptosis by cytotoxic dose of Hep88 mAb is mediated G2/M phase arrest and undergoing apoptosis via cascade reaction.

Previously gathered evidence has shown that Hep88 was targeted to the HCC cell line (Puthong et al., 2009). The alteration in morphological structure following Hep88 
mRNA Expression of Bax, Bcl-2, p53, Cathepsin b, Caspase-3 and Caspase-9 in the HepG2 Cell Line with Hep88 mAb

$\mathrm{mAb}$ treatment of HepG2 cells illustrated the intracellular vacuolization, endoplasmic reticulum and mitochondria dilation, which is the morphology of paraptosis-like PCD (Manochantr et al., 2011). The paraptosis-like PCD was explained by Sperandio et al. (Sperandio et al., 2000) and Wyllie and Golstein (Wyllie and Golstein, 2001), who described the cascade reaction of caspase-independent PCD. As a result, this pathway might be lacking some of the morphology of caspase-dependent PCD. However, many reports have now demonstrated that cell death might be accompanied by a multi-mechanism. The morphological nature of cell deaths depends on the most effective and fastest pathway (Leist and Jaattela, 2001)

From this point, the results of this study demonstrate that the effects of Hep88 mAb on apoptosis induction, cell cycle progression in HCC cell line were significantly increased in a dose- and time-dependent manner. As cells are entering the apoptosis state, the earliest feature of this activity is the phosphatidylserine translocation from the inner cytoplasmic membrane to the outer membrane, a movement which can be detected by annexin V staining. Our annexin V-PI staining data found a significant increase of an early apoptotic cell population with elevated concentration and prolonged exposure time (Figure 1). This increase correlates well with many pieces of evidence indicating that apoptosis induction not only involves an extrinsic (caspase- 8 activation) apoptosis pathway and a mitochondrial/intrinsic (Caspase-9 and Caspase-3 activation) apoptosis pathway (Mitupatum et al., 2015), but also induces cell cycle arrest as well (Lin et al., 2013; Wang et al., 2014b).

From within the scope of these patterns, the cell cycle can be determined by the quantization of DNA content (PI staining) within the cell. The cycle is based on differences in DNA content in each phase by following the cells in a pre-replicative phase (G1), replicate DNA- (S phase) and post-replicative plus mitotic (G2/M)-phase cells. Moreover, DNA content can be used to estimate apoptotic cells by sub-G1 (Darzynkiewicz et al., 2010). During the cell cycle, the potential target for cancer therapy is a G2/M checkpoint (Wang et al., 2009), because G2/M is a checkpoint that prevents DNA-damaged cells from entering mitosis and allows for the DNA repair. If cells cannot repair the damage during cell cycle arrest, the cell cycle progression with the DNA damage causes cell death or apoptosis (Wang et al., 2014a). As based on this point, it has been found that many publications on the novel cytotoxic molecule with regard to its role in cancer therapy are concerned with G2/M phase arrest (Lin et al., 2013; Wang et al., 2014b). Remarkably, our results revealed that Hep88 mAb induced HepG2 cells to arrest at the G2/M phase and to increase in the sub-G1 peak (Figure 2) in a concentration- and-time-dependent manner. This cell cycle data was correlated with significantly increased cell death, as determined by annexin $\mathrm{V}$ staining. As shown in the previous report, Hep88 mAb-specific protein is heat shock protein 70 (mortalin) (Rojpibulstit et al., 2014). Cell cycle data from our study might be explained by the result of mortalin depletion after recognition by Hep 88 $\mathrm{mAb}$. It induces the restoration of $p 53$-activating apoptosis induction and finally activates cell cycle arrest (Starenki et al., 2014).

Interestingly, the heat shock protein 70 (Hsp70) family is found at the lysosomes of many cancer cells and has been shown to prevent LMP (Nylandsted et al., 2004). Hsp70 has been shown to interact with Bax and prevent its translocation (Stankiewicz et al., 2005). Based on our recent report, its effect might be elucidated by the fact that, once Hep88 mAb interacted with Hsp70 mortalin, it may have subsequently resulted in recovering the cascade mechanism which conducted the apoptosis pathway. The postulated mechanism of Hep88 mAb may also be explained by the regaining of $p 53$-mediated apoptosis by withdrawal of Hsp70 mortalin action on $p 53$.

The existence of this mechanism is confirmed by the continual increase in fold change of p53 mRNA expression at 6- and 9-hr following treatment (Figure 5B). Subsequently, mortalin-freely-p53 thus induces transcription-dependent apoptosis through transcriptional activation of the pro-apoptotic gene Bax by the translocation of itself into a nucleus and induces apoptotic signals, as reported by Green and Kroemer (Green and Kroemer, 2009). The result of this study has also confirmed that it did show the correlation between the up-regulation of Bax and $p 53$ mRNA expression (Figure 5B). On the other hand, $p 53$ can also induce these effects through the transcriptionindependent apoptosis, which is mainly achieved by the interaction between $p 53$ and anti-apoptotic $\mathrm{Bcl}-2$ proteins. This response is actually the reaction to apoptotic stresses, which has this consequence: Cytoplasmic p53 consequently moves rapidly to the mitochondria, binds to anti-apoptotic $\mathrm{Bcl}-2$ proteins and then releases the proapoptotic Bax from the complex with the anti-apoptotic proteins. Subsequently, the released Bax mediates the mitochondrial outer membrane permeabilization (MOMP) and lysosomal membrane permeabilization (LMP) formation, which elicits cytochrome c (Green and Kroemer, 2009; Chiang et al., 2014) and lysosomal cathepsins release to the cytosol (Kagedal et al., 2005). From this study, it is suggested that up-regulation of Bax mRNA expression and down-regulation of $B c l-2$ mRNA expression at each time point in Hep88 mAb-treated HepG2 cells was induced by $p 53$.

On the other consequence, the overexpression of cathepsins has been demonstrated in numerous cancers (Gondi and Rao, 2013). The cathepsins are involved in either directed or indirected cell death. Cathepsin $B$ is an important cysteine protease enzyme, and is involved in either the progression of cancer cells or in cell proliferation; likewise, it is involved in apoptosis induction, especially in HCC. Previously, Foghsgaard et al. reported evidence for the role of cathepsins in the execution of caspase-independent cell death, resulting in a paraptosis-like morphology (Foghsgaard et al., 2001). This involvement correlated well with our results that, following the earliest Hep88 mAb treatment, the rapid up-regulated Cathepsin B (CTSB) mRNA expression is strongly expressed at $3 \mathrm{hr}$ of incubation (Figure 5D). Additionally, our data has shown that mRNA expression of Cathepsin B is up-regulated again at 9- and 18-hr of treatment (Figure 4C and 5D). However, when monitoring the Cathepsin B mRNA expression at the end of a 24- 
hr period following treatment, down-regulation was observed. This result corresponds well with the report shown by Malla et al. that down-regulation of Cathepsin $B$ could initiate caspase-dependent cell death by decreases in the $B c l-2 / B a x$ ratio and also induce the activation of Caspase- 9 and Caspase- 3 in the brain-cancer cell line (Malla et al., 2010).

From all of these data, it can be concluded that Hep88 mAb treatment induces paraptosis until the development of apoptosis with this consequence: At the early stage of Hep88 mAb treatment (3-hr), HepG2 cells suddenly up-regulated the Cathepsin $B$ mRNA expression. Overexpressed Cathepsin $B$ mRNA was transported from the nucleus, packed in the lysosomes and then released to cytosol from the external induction. It contributed to loss of mitochondria membrane potential and the releasing of cytochrome c (Guicciardi et al., 2000). The intrinsic apoptotic pathway was subsequently initiated by the up-regulation of Capase- 9 and Caspase- 3 mRNA, which correlated well with the previous reports (Joy et al., 2010). The death induction was further stimulated after the binding of Hep88 mAb to its specific antigen (Ag), which might correspond with the death receptor at the cell membrane. The extrinsic apoptotic pathway was subsequently induced (Guicciardi et al., 2000). However, at this time point, Cathepsin B wasn't completely released because LMP was suppressed by Hsp70 mortalin-Bax and Hsp70 mortalin-p53 binding complexes (Taurin et al., 2002; Stankiewicz et al., 2005; Wadhwa et al., 2006). Taurin and co-workers found that the p53 expression in mortalin-transfected cells was delayed in its response to death induction (Taurin et al., 2002). Moreover, Stankiewicz et al. also found that Hsp70 blocks heat-induced apoptosis by inhibiting Bax activation (Stankiewicz et al., 2005). For this reason, Hep88 mAbtreated HepG2 cells did not show the $p 53$ and Bax mRNA up-regulation for three hours.

At 6-hr of treatment, the cancer cell attempts to combat and escape from the death induction of Hep88 mAb-treatment by the up-regulated $\mathrm{Bcl}-2 \mathrm{mRNA}$ expression. As a result, MOMP and LMP were suppressed in their release of cytochrome $\mathrm{c}$ and Cathepsin B. This suppression probably means that the cancer cells have adapted themselves to avoid harm when exposed to the treatment. As related in many reports, it was demonstrated that an over-expression of $\mathrm{Bcl}-2$ has been found to be associated with apoptotic resistance to anti-cancer treatment (Sartorius and Krammer, 2002; Douarre et al., 2005). Sartorius and Krammer found that the strongly upregulated $\mathrm{Bcl}-2$ paralleled the apoptotic resistance in lungcancer cell lines after treatment with anti-cancer drugs (Sartorius and Krammer, 2002). In addition, Douarre et al. demonstrated that transfected $\mathrm{Bcl}-2$ in lung-cancer cell lines resisted the apoptosis cell-death induction (Douarre et al., 2005). Moreover, Hep88 mAb treatment at this time point showed that the balance between anti-apoptosis and apoptosis occurred like a seesaw board; we explored the up-regulated $\mathrm{Bcl}-2 \mathrm{mRNA}$ that caused the remarkable reduction in the regulation of Cathepsin B, Caspase- 9 and Caspase- 3 mRNA in the HepG 2 cell. Meanwhile, the death induction in this study was still further stimulated through extrinsic apoptotic PCD. Bid was truncated and directly allowed the release of cytochrome $\mathrm{c}$ to induce Caspase-9 (Chipuk and Green, 2008). So, we were able to find the Caspase- 9 mRNA expression in the Hep88 mAb-treated cell. At the same time, Hep88 mAb might be fully internalized into the HepG2 cell, as it was widely reported (Walter et al., 2005). It was then binding itself to Hsp70 mortalin to restore $p 53$-function. In that way, p53 mRNA was beginning to be up-regulated. Similarly, as Walker and colleagues have reported, the molecule specific to mortalin also induced $p 53$ by stealing it from the p53-mortalin complex (Walker et al., 2006).

A still larger amount of Hep $88 \mathrm{mAb}$ was then internalized into the HepG2 cells. At 9-hr of incubation, the Hsp70 mortalin-p53 complex in cytoplasm was reduced. $p 53$ was thus freely capable of translocation into the nucleus. Those cells of the up-regulated p53 then induced transcription-dependent apoptosis through transcriptional activation of the pro-apoptotic gene Bax. As shown in the results, Cathepsin B, Caspase-3, p53 and Bax mRNA expression were drastically increased.An overt up-regulation of $\mathrm{Bcl}-2 \mathrm{mRNA}$ also came into sight. This state initiated the signaling of a pathway of gradual inhibition of LMP and MOMP. They were modified into a seesaw board balance between anti-apoptosis and apoptosis, which still occurred. Nevertheless, the strongest expression can show its power to affect the cells. Cathepsin B was gradually increased and released from lysosome such that the dead-escape phenomenon could no longer withstand it. For this reason, when mitochondrialmediated caspase route did not work, most of the cell death at this time point was induced through Cathepsin $B$ activity that caused caspase-independent PCD or paraptosis (Broker et al., 2004). On the other hand, apoptosis was still stimulated through the extrinsic apoptotic pathway so that we could see the up-regulated levels of Caspase-3 mRNA expression in our results.

With a prolonged incubation time of the Hep88 mAb-treated HepG2 cell extending to 12-hr, the death induction was altered, and was mainly induced through mitochondrial-mediated caspase that led to apoptosis. It was caused by the damage that had accumulated in the cell from the previously released Cathepsin $B$ and other lysosomal proteases activities. Further, it may precede the mitochondria dysfunction by exhibiting the cytochrome $\mathrm{c}$ release (Nylandsted et al., 2004) and may also represent a common mechanism for $p 53$-dependent apoptosis (Joy et al., 2010). From our results, we disclosed the fact that the up-regulation of Bax and Caspase-9 correlated well with $p 53$ mRNA expression. Meanwhile, Cathepsin B and $B c l-2$ mRNA expression were down-regulated to allow cell death through apoptosis. It is possible that the DNA damage response led to $p 53$ accumulation in the nucleus. Nuclear p53 transactivated the pro-apoptotic gene Bax to stimulate entering into the intrinsic apoptotic pathway.

At 18-hr of our treatment program, the data showed the Cathepsin B mRNA expression to be outstandingly upregulated once again. It is possible that the Hsp70 mortalin increased by adaptive response to high intracellular stress and was sequestered to cytoplasmic p53 (Taurin et al., 2002). As a result, $p 53$ cannot translocate back into the 
mRNA Expression of Bax, Bcl-2, p53, Cathepsin b, Caspase-3 and Caspase-9 in the HepG2 Cell Line with Hep88 mAb

nucleus. So, our results demonstrated the down-regulated p53. However, Bax and Caspase-9 mRNA expressions were also up-regulated by the remaining $p 53$. Several studies have shown that cytoplasmic $p 53$ associates with mitochondria-mediated caspase. p53 settles in the mitochondrial membrane after an importation step involving mortalin-p53 complex (Marchenko et al., 2000). Furthermore, at this moment in our study, the $B c l-2 / B a x$ expression ratio fell to a value lower than one, indicating that MOMP and LMP had occurred. Therefore, the death induction in the HepG2 cell in this place was induced through both Cathepsin B and mitochondriamediated caspase that can lead to paraptosis and apoptosis respectively.

When HepG2 was treated with Hep88 mAb for 24-hr, p53, Bax, Caspase-9 and Caspase-3 mRNA expressions were markedly detectable, while the paraptosis engagement protein Cathepsin B and the anti-apoptotic Bcl-2 mRNA expression were observed conversely. Especially, the tumor suppressor p53 mRNA was impressively overexpressed, and the effector caspases Caspase-3 mRNA expression was shown to have a greater increase than at the earlier time point. This evidence is supported in the death induction by Hep 88 mAb in the HepG 2 cell, which was induced through caspase-dependent PCD. It correlates well with our previous report that it is the fastest mechanism - namely, the predominant death morphology verification. All of the results from this study confirm the cytotoxic mechanism of Hep88 mAb that it triggered HCC to be death via the onset of paraptosis, which continued till the development of apoptosis.

In conclusion, Hep88 mAb caused apoptosis induction in a time- and dose-dependent manner. A cytotoxic dose of the Hep 88 mAb-treated HepG 2 cell is mediated by G2/M phase arrest and the undergoing paraptosis and apoptosis. These processes take place via the cascade reaction. Although, the mRNA expression is an informative data, the study at protein level must be further investigated to confirm this mechanism in the future. The interesting outcomes of our study have revealed the possibility of the Hep88 mAb mechanism as affecting the induction program that led to the cell death of HCC.

\section{Acknowledgements}

This research was financially supported by a research grant from the Faculty of Medicine, Thammasat University. TM was supported by a Thammasat University Ph.D. Program scholarship.

\section{References}

Broker LE, Huisman C, Span SW, et al (2004). Cathepsin $B$ mediates caspase-independent cell death induced by microtubule stabilizing agents in non-small cell lung cancer cells. Cancer Res, 64, 27-30.

Chiang KC, Tsui KH, Chung LC, et al (2014). Cisplatin modulates B-cell translocation gene 2 to attenuate cell proliferation of prostate carcinoma cells in both $p 53$ dependent and $p 53$-independent pathways. Sci Rep, 4, 5511.

Chipuk JE, Green DR (2008). How do Bcl-2 proteins induce mitochondrial outer membrane permeabilization? Trends
Cell Biol, 18, 157-64.

Darzynkiewicz Z, Halicka HD, Zhao H (2010). Analysis of cellular DNA content by flow and laser scanning cytometry. Adv Exp Med Biol, 676, 137-47.

Douarre C, Gomez D, Morjani H, et al (2005). Overexpression of $\mathrm{Bcl}-2$ is associated with apoptotic resistance to the G-quadruplex ligand 12459 but is not sufficient to confer resistance to long-term senescence. Nucleic Acids Res, 33, 2192-203.

Foghsgaard L, Wissing D, Mauch D, et al (2001). Cathepsin B acts as a dominant execution protease in tumor cell apoptosis induced by tumor necrosis factor. J Cell Biol, 153, 999-1010.

Gondi CS, Rao JS (2013). Cathepsin B as a cancer target. Expert Opin Ther Targets, 17, 281-91.

Green DR, Kroemer G (2009). Cytoplasmic functions of the tumour suppressor $p 53$. Nature, 458, 1127-30.

Guicciardi ME, Deussing J, Miyoshi H, et al (2000). Cathepsin $B$ contributes to TNF-alpha-mediated hepatocyte apoptosis by promoting mitochondrial release of cytochrome c. J Clin Invest, 106, 1127-37.

Joy B, Sivadasan R, Abraham TE, et al (2010). Lysosomal destabilization and Cathepsin B contributes for cytochrome c release and caspase activation in embelin-induced apoptosis. Mol Carcinog, 49, 324-36.

Kagedal K, Johansson AC, Johansson U, et al (2005). Lysosomal membrane permeabilization during apoptosis--involvement of Bax? Int J Exp Pathol, 86, 309-21.

Laohathai K, Bhamarapravati N (1985). Culturing of human hepatocellular carcinoma. A simple and reproducible method. Am J Pathol, 118, 203-8.

Leist M, Jaattela M (2001). Four deaths and a funeral: from caspases to alternative mechanisms. Nat Rev Mol Cell Biol, 2, 589-98.

Lin CH, Lu WC, Wang CW, et al (2013). Capsaicin induces cell cycle arrest and apoptosis in human KB cancer cells. BMC Complement Altern Med, 13, 46.

Malla R, Gopinath S, Alapati K, et al (2010). Downregulation of uPAR and Cathepsin $B$ induces apoptosis via regulation of $B c l-2$ and $B a x$ and inhibition of the PI3K/Akt pathway in gliomas. PLoS One, 5, 13731.

Manochantr S, Puthong S, Gamnarai P, et al (2011). Hep 88 $\mathrm{mAB}$ induced ultrastructural alteration through apoptosis like program cell death in hepatocellular carcinoma. J Med Assoc Thai, 94, 109-16.

Marchenko ND, Zaika A, Moll UM (2000). Death signal-induced localization of $p 53$ protein to mitochondria. A potential role in apoptotic signaling. J Biol Chem, 275, 16202-12.

Mitupatum T, Aree K, Kittisenachai S, et al (2015). Hep88 mAb-Mediated Paraptosis-Like Apoptosis in HepG2 Cells via Downstream Upregulation and Activation of Caspase-3, Caspase-8 and Caspase-9. Asian Pac J Cancer Prev, 16, 1771-9.

Nylandsted J, Gyrd-Hansen M, Danielewicz A, et al (2004). Heat shock protein 70 promotes cell survival by inhibiting lysosomal membrane permeabilization. J Exp Med, 200, 425-35.

Puthong S, Rojpibulstit P, Buakeaw A ( 2009). Cytotoxic effect of Hep88 mAb: a novel monoclonal antibody against hepatocellular carcinoma. Thammasat Int J Sc Tech, 14, 95-104.

Rojpibulstit P, Kittisenachai S, Puthong S, et al (2014). Hep88 $\mathrm{mAb}$-initiated paraptosis-like PCD pathway in hepatocellular carcinoma cell line through the binding of mortalin (HSPA9) and alpha-enolase. Cancer Cell International, 14.

Sartorius UA, Krammer PH (2002). Upregulation of Bcl-2 is involved in the mediation of chemotherapy resistance in human small cell lung cancer cell lines. Int J Cancer, 97, 

584-92.

Sperandio S, de Belle I, Bredesen DE (2000). An alternative, nonapoptotic form of programmed cell death. Proc Natl Acad Sci U S A, 97, 14376-81.

Sperandio S, Poksay K, de Belle I, et al (2004). Paraptosis: mediation by MAP kinases and inhibition by AIP-1/Alix . Cell Death Differ, 11, 1066-75.

Stankiewicz AR, Lachapelle G, Foo CP, et al (2005). Hsp70 inhibits heat-induced apoptosis upstream of mitochondria by preventing Bax translocation. J Biol Chem, 280, 38729-39.

Starenki D, Hong SK, Lloyd RV, et al (2014). Mortalin (GRP75/ HSPA9) upregulation promotes survival and proliferation of medullary thyroid carcinoma cells. Oncogene.

Taghiyev A, Sun D, Gao ZM, et al (2012). Embelin-induced apoptosis of HepG2 human hepatocellular carcinoma cells and blockade of HepG2 cells in the G2/M phase via the mitochondrial pathway. Exp Ther Med, 4, 649-54.

Taurin S, Seyrantepe V, Orlov SN, et al (2002). Proteome analysis and functional expression identify mortalin as an antiapoptotic gene induced by elevation of $[\mathrm{Na}+] \mathrm{i} /[\mathrm{K}+] \mathrm{i}$ ratio in cultured vascular smooth muscle cells. Circ Res, 91, 915-22.

Wadhwa R, Takano S, Kaur K, et al (2006). Upregulation of mortalin/mthsp70/Grp75 contributes to human carcinogenesis. Int J Cancer, 118, 2973-80.

Walker C, Bottger S, Low B (2006). Mortalin-based cytoplasmic sequestration of $p 53$ in a nonmammalian cancer model. Am J Pathol, 168, 1526-30.

Walter RB, Raden BW, Kamikura DM, et al (2005). Influence of CD33 expression levels and ITIM-dependent internalization on gemtuzumab ozogamicin-induced cytotoxicity. Blood, 105, 1295-302.

Wang H, Zhang J, Sit WH, et al (2014a). Cordyceps cicadae induces G2/M cell cycle arrest in MHCC $97 \mathrm{H}$ human hepatocellular carcinoma cells: a proteomic study. Chin Med, 9, 15.

Wang Y, Ji P, Liu J, et al (2009). Centrosome-associated regulators of the $\mathrm{G}(2) / \mathrm{M}$ checkpoint as targets for cancer therapy. Mol Cancer, 8,8 .

Wang YX, Cai H, Jiang G, et al (2014b). Silibinin inhibits proliferation, induces apoptosis and causes cell cycle arrest in human gastric cancer MGC803 cells via STAT3 pathway inhibition. Asian Pac J Cancer Prev, 15, 6791-8.

Whelan JA, Russell NB, Whelan MA (2003). A method for the absolute quantification of cDNA using real-time PCR. Journal of Immunological Methods, 278, 261-9.

Wyllie AH, Golstein P (2001). More than one way to go. Proc Natl Acad Sci U S A, 98, 11-3. 